\title{
DIZER-MOSTRANDO NA EXPERIÊNCIA DE REALIZAÇÃO DE UM DOCUMENTÁRIO ETNOGRÁFICO ${ }^{1}$
}

\author{
Jenniffer Simpson dos Santos ${ }^{2}$ - simpson.jenniffer@gmail.com
}

\section{RESUMO}

Os discursos colonialista, capitalista e patriarcal são hábeis em manter viva uma memória que recorta e preserva somente aquilo que lhes interessa, deixando claro que uma disputa narrativa também é uma disputa de mundos. Uma vez que não há aleatoriedade na produção social de lembranças e de esquecimentos, convocar vozes e corporalidades que não ficaram ou não ficariam gravadas como história é uma forma de dialogar, opondo-se ao logocentrismo e a uma tradição hegemônica de violências. Este ensaio tem por objetivo refletir acerca dos diversos modos de dizer enquanto experiência incorporada a partir da realização de um documentário etnográfico.

PALAVRAS-CHAVES: Experiência; Dizer-mostrando; Documentário etnográfico.

\begin{abstract}
Colonialist, capitalist and patriarchal speeches are able to keep alive a memory that cuts out and preserves only what interests them, making it clear that a narrative of struggle is also a dispute of worlds. Since there is no variability in the social production of memories and oblivion, summoning up voices and corporealities that were not or would not be recorded as part of History is a way of establishing dialogues, opposing them to the logocentrism and to a hegemonic tradition of violence. This text aims to reflect about different ways of expression while in incorporated experience, from the analysis of an ethnographic documentary.
\end{abstract}

KEYWORDS: Tell-showing; Experience; Ethnographic documentary.

\section{INTRODUÇÃO}

Engana-se a leitora ou o leitor que, por acaso, chegou a este ensaio com o propósito de encontrar dicas de como realizar um documentário. Para este fim, há uma vasta bibliografia sobre o tema. A mim, cabe refletir aqui sobre uma experiência que me marcou durante a realização do meu doutorado em Sociologia. O período foi de 2011 a 2017, na cidade de Coimbra, com trabalho de campo feito em Manaus. Ao exercitar essa reflexão, o meu corpo se enche de memórias cujas emoções recuperadas transitam entre as dores grandes e as dores menos grandes de tal processo. Isso se materializa numa acidez no estômago que chega a boca. É com essa sensação amarga na língua que escrevo estas palavras.

\footnotetext{
${ }^{1}$ Este texto resulta da minha investigação de Doutorado em Sociologia (SANTOS, 2019a), realizada na Faculdade de Economia da Universidade de Coimbra. A pesquisa beneficiou-se de financiamento concedido pela Coordenação de Aperfeiçoamento de Pessoal de Nível Superior (CAPES), no âmbito do Programa Doutorado Pleno no Exterior, vinculado ao Ministério da Educação do Brasil.

${ }^{2}$ Doutora em Sociologia pela Universidade de Coimbra. Professora da Universidade Federal da Grande Dourados.
} 


\section{Nanduty}

ISSN:2317-8590

Muitos escritores e escritoras, entre os/as quais um dos meus preferidos, Cristóvão Tezza, costumam falar que a escrita ficou reservada para as pessoas infelizes que se trancam num quarto para escrever. As pessoas felizes, continua Tezza, vão ao cinema, namoram, etc. É claro que também fui ao cinema (muito) e namorei (não tanto quanto gostaria), mas não foi com isso que a tese se concretizou. Isso faz parte dos momentos de intervalo e me recuso a aceitar que em tais momentos eu também trabalhava para a tese, como anseia o capitalismo atual.

Dito isso, parece-me ter ficado claro que este relato está limitado pelo campo acadêmico, que precisa dar conta de objetivos minimamente definidos, acompanhados por um dado procedimento metodológico e com prazos cada vez mais reduzidos. Ao longo da escrita da tese, também foi realizado o documentário Lutas artesanais como forma de elucidação do processo de luta das artesãs do Amazonas a partir das suas próprias corporalidades, cujos bastidores trago aqui. O propósito deste texto é o de refletir acerca dos diversos modos de dizer enquanto experiência incorporada a partir da realização de tal documentário.

Em síntese, Lutas artesanais apresenta as trajetórias de mulheres indígenas de duas associações em Manaus: Associação das Mulheres Indígenas do Alto Rio Negro (AMARN) e na Associação das Mulheres Indígenas Sateré-Mawé (AMISM). Em seus percursos, as artesãs vão constituindo formas próprias de organização da vida e, ao mesmo tempo, vão mostrando suas formas de saber-fazer a partir da prática do artesanato.

\section{O FAZER E O OLHAR: LUTAS ARTESANAIS [BRASIL, 2015, 50 MIN.]}

A luta das mulheres indígenas é uma coisa que não é pra ser esquecida. Uma coisa que veio de muito tempo. Conseguiu chegar até aqui, está segurando a associação, segurando as familias. Então, por que é importante gravar isso, gravar na memória? Porque eu sei, eu vivi, eu estou vendo a necessidade, mas muitos que virão, não vão saber contar nem a história? Então, está gravado? Tá, vão ver. Ouvir de novo pra ver... Olha, foi dessa maneira que a gente conseguiu chegar até aqui. (JUCENILDA, Lutas artesanais).

Com essas palavras, a artesã Jucenilda enuncia o objetivo principal da produção do documentário. 


\section{Nanduty}

ISSN:2317-8590

Aprendi com dona Baku que escolhemos por onde começar a contar uma história. Então, escolho começar a falar sobre a realização do documentário pelo seu fim. Lutas artesanais termina com dona Baku dizendo, em sua língua sateré-mawé, que ela mesma traduz: “Agora, você está aqui procurando conversa, mas, quando você estiver longe, não se esqueça das artesãs indígenas". Em seguida, ela calça o seu chinelo e vai embora cuidar do almoço. A câmera permanece filmando o chão, e, de repente, uma folha gira para um lado e para o outro, como se esse chão reafirmasse a despedida. Depois de almoçarmos juntas, regressei a Coimbra e não voltei a encontrá-la, dona Baku morreu meses depois, mas as suas palavras indeléveis permanecem comigo. E a gravação desse alerta que dona Baku me faz também não me deixa esquecer o tom de sua voz, seu ritmo, seus movimentos e os artesanatos que já fazem parte do seu corpo.

Antes disso, declara a artesã Regina, em determinado momento do documentário: "Toda semente tem um significado, um porquê e tudo mais". Sua afirmação é o motivo para que, logo em seguida, a artesã explique que as sementes são vida e protegem o corpo. Mas Regina não se limita a explicar, ela diz-mostrando uma a uma, falando dos poderes de suas sementes, em que áreas elas podem ser encontradas e ainda qual é a sua aplicação em cada peça de artesanato produzida por ela e pelas outras mulheres da associação.

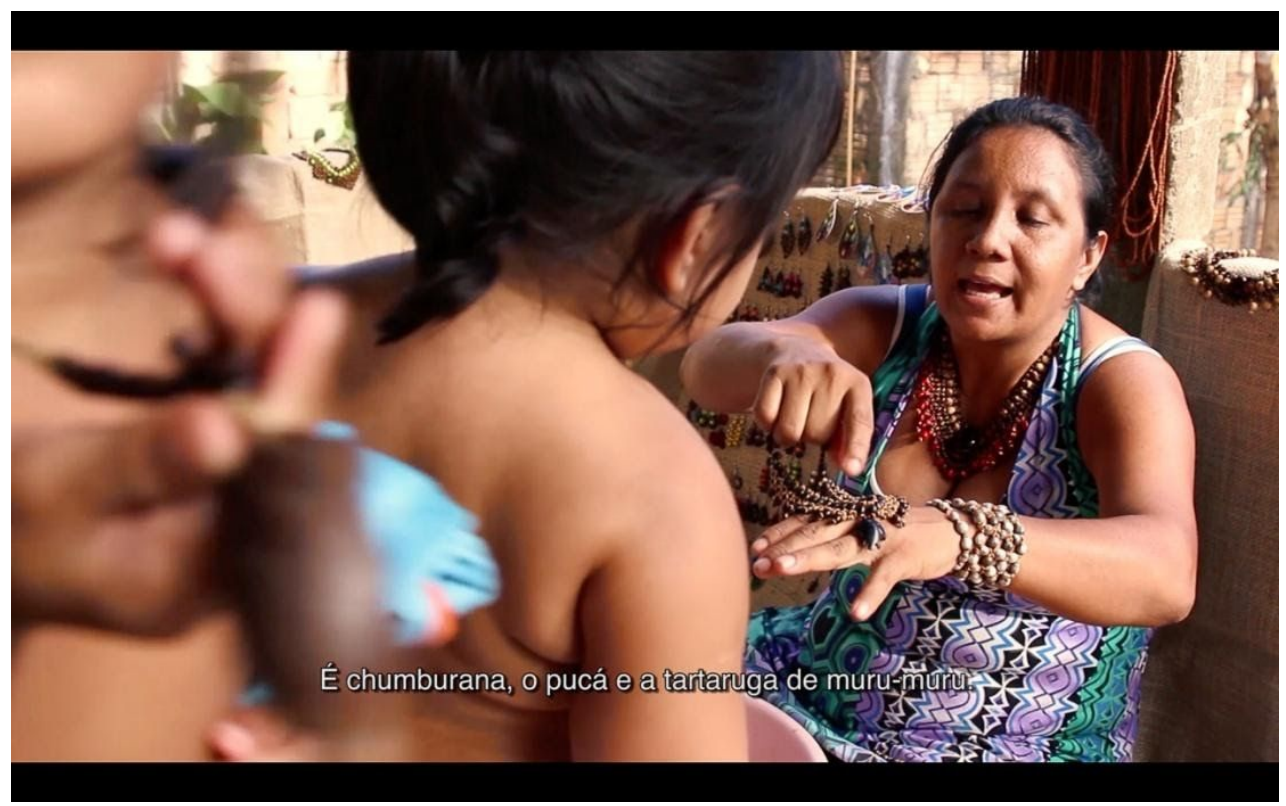

Fotograma de Lutas artesanais. 


\section{Nanduty}

ISSN:2317-8590

Com isso, Regina põe em causa qualquer pretensa dicotomia entre imagem e linguagem, uma vez que é possível verificar que a mensagem visual participa na construção da linguagem, mas também a transmite e a completa, mediante uma complementaridade tanto reflexiva quanto criadora. Como diz Jean-Luc Godard, "a imagem é uma forma que pensa e um pensamento que forma".

Quando Baku conta a história do colar que mantém no seu pescoço há mais de 40 anos, ela refere a materialidade do colar como testemunho de sua própria história.

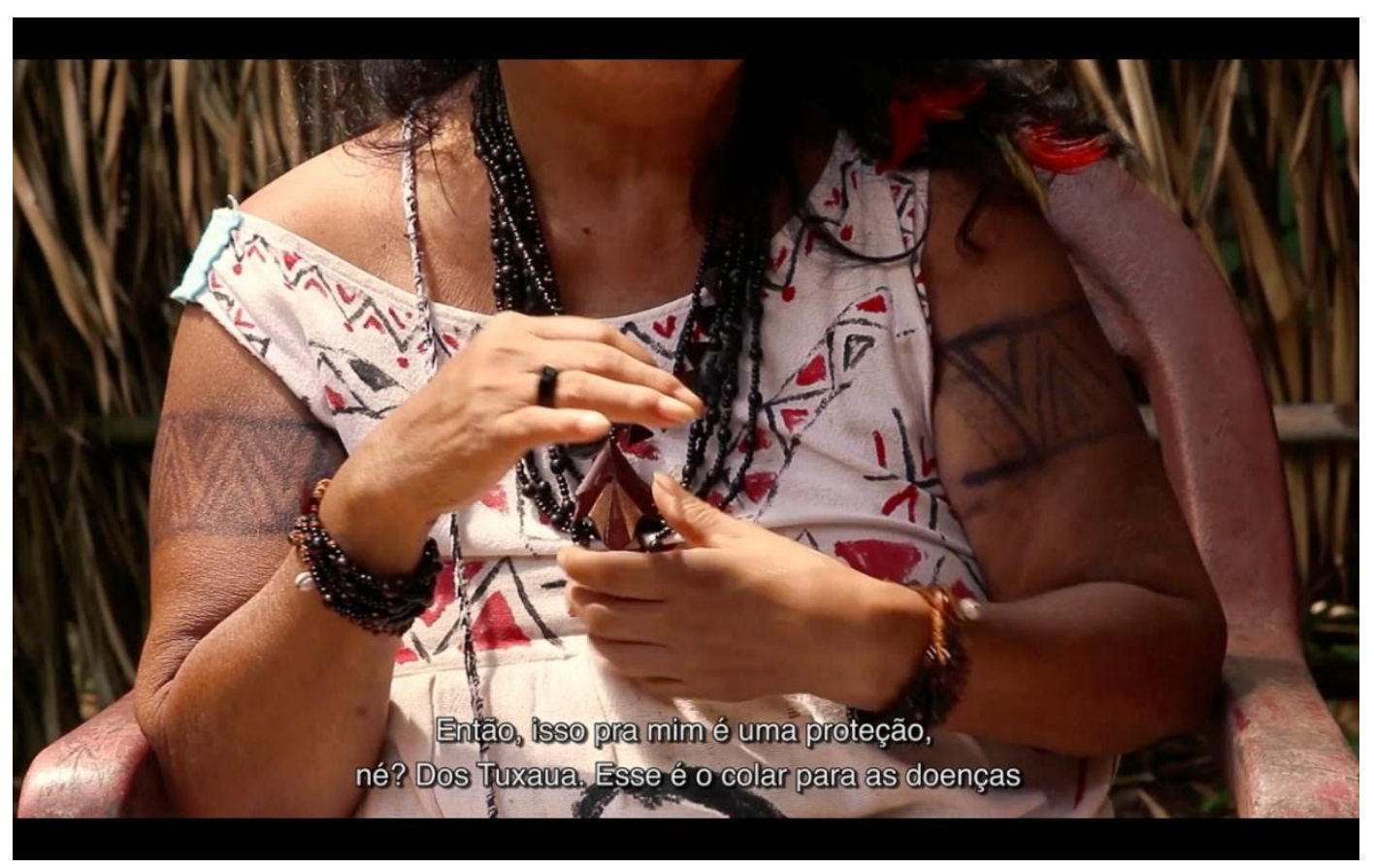

Fotograma de Lutas artesanais.

Um colar que se converteu em amuleto e que representa a sua atual função - tuxaua. Ao tocá-lo, a história é narrada:

Este colar aqui no ano de... Não sei nem que ano, nós fomos numa assembleia em Maués, eu, ela [Zenilda], aí lá, dentro, lá no monte Orebe, o Tuxaua botou em nós duas, e ele disse: [fala em sateré-mawé] "Tá aqui esse colar para vocês, vocês vão subir muito alto, então, vocês tenham muito cuidado com esse colar". Botou no meu pescoço e no dela. O dela, ela perdeu na hora que ela foi tomar banho de tarde, ela perdeu na praia, mas o meu está aqui. (BAKU, Lutas artesanais).

Baku associa a morte prematura de sua irmã Zenilda à perda do colar. Logo em seguida, começou a explicar, um a um, os poderes dos artesanatos que trouxera em seu corpo: 


\section{Nanduty}

ISSN:2317-8590

"Esse é o colar para as doenças. Esse colar é proteção... Aqui tem, ó: caramuri significa o tuxaua, né? Pena, proteção contra doença. Então, eu uso... Pra mim, sem esses daqui...”, completa dizendo "não" com a cabeça. Quando a questiono sobre as pinturas, explica-me com um exemplo: "Vocês, quando vão para uma festa, não se embelezam, né? Então, nós também. É nossa beleza e proteção também”. São esses saberes incorporados das artesãs indígenas que eu gostaria de trazer para discussão no espaço acadêmico por meio da narrativa audiovisual, que possibilita dizer e mostrar ao modo dessas mulheres. E aqui aparece o segundo objetivo que mobilizou a produção do filme.

Quando me propus a fazer o documentário, já sabia que seria muito trabalhoso. Passei dezenas de horas às voltas com ele. Tive de comprar equipamentos, pois as câmeras que havia usado para produzir meus dois primeiros documentários eram da instituição à qual estava vinculada na época.

Optei pela câmera fotográfica por causa da boa qualidade da imagem, comparada a filmadoras com preço semelhante. Embora a câmera fotográfica não permita gravar mais do que 12 minutos consecutivos (devido a questões comerciais, para gerar a necessidade de dois objetos distintos), sua qualidade de imagem e versatilidade compensam a restrição temporal. O fato de trabalhar com 12 minutos de gravação não foi um problema, uma vez que o gravador externo garantiu a integridade do áudio.

Antes de iniciar a filmagem, explicava sobre essa limitação do equipamento e pedia a compreensão e paciência das artesãs nesse processo. Com o decorrer das gravações, esse intervalo do equipamento foi integrado na dinâmica da entrevista. Em alguns momentos, elas também mediam o tempo e criavam alguma situação para dar-me espaço de reiniciar o processo. "Vou ali estender a roupa" ou "vou ao banheiro rapidinho, espera aí", diziam. Isso, quando ocorria, era no intervalo da câmera. Em muitos casos, reiniciar a gravação acontecia de maneira rápida, sem dar importância ao fato. Em outros momentos, eu aproveitava esse intervalo "da roupa ou do banheiro" para mudar a câmera de lugar e gravar detalhes do cotidiano da associação. Isso torna a cena mais dinâmica e privilegia vários ângulos, parecendo que o filme foi gravado com várias câmeras. Entretanto, reposicionar a câmera é mudar tudo: reajustar o som e a luz, sem perder a linha narrativa. Elas viam o quanto era 


\section{Nanduty}

ISSN:2317-8590

laborioso, e isso nos aproximava. A partir daí, já não sabia quem era a observadora e quem era a observada. Em todo o processo de gravação, tive a cumplicidade e o apoio das artesãs. Certa vez, durante um desses intervalos da entrevista, Regina perguntou para mim: "será que eu estou falando alguma coisa que vai servir para o teu trabalho?”. Alegrei-me com a preocupação e o cuidado de Regina e respondi que estava muito melhor do que eu imaginava. Então, de 12 em 12 minutos, foram realizadas mais de 50 horas de gravação.

Posicionar a câmera no tripé foi necessário, pois as gravações foram feitas somente por mim. Tinha de cuidar do som, da iluminação, da fotografia e da entrevista. Por isso, posicionava-me por detrás dos equipamentos. Todo o filme foi gravado com uma única câmera de fotografar que também filma. Embora as gravações tenham sido realizadas integralmente apenas por mim, um documentário é um trabalho coletivo, cujo resultado depende da qualidade da relação criada. Tais relações, assim como as expectativas das artesãs quanto ao filme, foram sendo forjadas relativamente aos resultados da investigação e conferiram à minha presença nas associações uma dimensão de troca. Nesse sentido, meu trabalho constituía, por um lado, uma possibilidade de as artesãs registrarem seus testemunhos. ${ }^{3}$ Aproveitando a presença da câmera e de uma investigadora, buscaram deixar para as gerações seguintes as suas experiências como parte de uma história que ajudaram a construir. Por outro, constituía também uma possibilidade de divulgação do artesanato, como enfatiza uma artesã:

\footnotetext{
${ }^{3}$ Com o surgimento da fotografia, na primeira metade do século XIX, uma nova forma de perceber e de materializar o que é visto foi inaugurada. Isso porque, pela primeira vez, o olho assumiu uma tarefa que era exclusiva da mão, como bem mostrou Walter Benjamin (2006). Por essa característica de aparição quase instantânea da representação do objeto, Roland Barthes (2015) argumenta que a fotografia está mais no âmbito da magia do que no da arte por se tratar de uma emanação do passado e não de uma cópia. Mas, sobretudo, o que a fotografia trouxe foi uma nova forma de se relacionar com a memória e de produzir memória social. Assim, a fotografia apresenta também um interesse histórico. Uma vez que permite a revisitação de materialidades expostas por uma determinada sociedade, conferindo um duplo testemunho (daquilo que retrata e de quem a retrata), como refere Boris Kossoy. Com essas peculiaridades de representação, não demorou para a fotografia ser usada pelas ciências sociais como documento e como instrumento de investigação. Um desses usos é por meio de uma fotoetnografia. Achutti (1997) chamou de fotoetnografia a utilização da fotografia como um instrumento narrativo que documenta aspectos culturais numa perspectiva etnográfica.
} 


\section{Nanduty}

ISSN:2317-8590

É importante também pra divulgar. Porque a gente tem aqui o local, tem essas feirinhas, essas exposições, mas se divulgar para mais longe. O artesanato, o recurso vai aumentar, e vai ter como ajudar não só as famílias, até a associação também, porque agora estamos mantendo só as famílias. Não está dando para ajudar a associação. Está só dando para ajudar o transporte para ir. Correr atrás das reuniões, das palestras, das exposições, mas não está dando pra uma ajuda maior (JUCENILDA, Lutas artesanais).

É importante deixar claro que o objetivo de tal divulgação não é simplesmente ampliar a venda. Uma divulgação é desejada, sobretudo, pela busca de um mercado justo, uma vez que a prática do artesanato é incompatível com a produção em larga escala.

O filme serve-se de diversos tipos de planos (gerais, de conjunto, de detalhe e, por vezes, também médios) para mostrar às mulheres nas mais variadas situações de trabalho e do cotidiano. Os ângulos escolhidos para posicionar a câmera buscaram destacar os protagonismos das artesãs. Para isso, a câmera posicionava-se na altura dos olhos das artesãs ou de baixo para cima, numa perspectiva frontal ou lateral, com o propósito de valorizá-las. Em nenhum momento, a câmera foi posicionada de cima para baixo. Se a artesã se sentava no chão para fazer o artesanato, era para o horizonte de seus olhos que a câmera ia.

A presença da câmera de filmar não foi vista como intimidatória. Como disse anteriormente, as artesãs sabiam que eu iria usar a câmera como um instrumento para contar um pouco da história delas e da associação e contribuíram ativamente para esse propósito. Durante todo o processo de filmagem, senti-me bastante confortável. Evitava apenas fazer gravações na rua, por uma questão de segurança. Certa vez, fui ao mercado com a artesã Claudinéia e, como estava com a câmera na mochila e não me senti segura em deixá-la no carro enquanto íamos às compras, decidi levar a mochila comigo. Claudinéia percebeu minha preocupação e disse: "eu não preciso ficar preocupada porque não tenho nada para me roubarem". O interessante foi que Claudinéia me disse isso rindo e continuou caminhando com as mãos soltas. Fui atrás dela, tentando não a perder naquela agitação do mercado no horário da compra para o almoço, mas confesso que o peso da mochila se fez presente em mim durante toda a feira.

Como sabia que estava produzindo imagens que seriam trabalhadas em outro continente e que não teriam a possibilidade de "emendas" posteriores caso faltasse material fílmico, 


\section{Nanduty}

ISSN:2317-8590

procurei registrar vários detalhes do cotidiano das associações. Isso ajudou a compor as cenas do filme e, ao mesmo tempo, não o restringiu a entrevistas.

Preferi não usar uma voz over, que geralmente é utilizada como guia em documentários. Essa decisão deve-se a dois motivos. Por um lado, faço uso do audiovisual como uma forma de entrar em contato com a outridade, e não para explicá-la, e essa forma de olhar manifestou-se diretamente no trabalho de edição. ${ }^{4}$ Por outro lado, tal escolha foi tomada para não reforçar a hegemonia da verbalização. Sempre achei estranha aquela voz despregada do acontecimento que narra um fenômeno terceiro. Não quis eu mesma contar a história e ir colocando fragmentos das entrevistas de modo a reforçar meu argumento. Recusei aproximar-me do documentário jornalístico tradicional, que usa frequentemente esse recurso. Os momentos em que minha voz aparece no filme são aqueles em que participo da cena em um diálogo, apesar de não aparecer visualmente por estar atrás da câmera, cuidando da imagem, do som, da luz e da entrevista.

Claro que uma voz over pode ser bem utilizada, mas não fazia sentido usá-la, pois teria toda a circunscrição de uma tese para explorar minhas próprias palavras. Então, preferi usar o espaço do documentário como uma forma de valorizar os modos de dizer das artesãs. Isso me gerou uma enorme complicação, já que eu teria de montar a narrativa apenas a partir das próprias artesãs. Criar conexões e uma coerência interna no filme sem usar uma voz diretiva colocou-me diante do desafio de contar a trajetória das duas associações, cruzando suas histórias, mas deixando claro que se tratava de duas associações distintas. A unidade narrativa do filme foi possível porque há uma luta comum - a luta pela sobrevivência de um modo de vida e de uma prática - que congrega uma sucessão de depoimentos, os quais me foram confiados para fazer o trabalho do recorte e da montagem. Alguns realizadores e realizadoras, com influência da escola de Göttingen, defendiam que a veracidade de um filme etnográfico se dava pela longa sequência, plano aberto, pela ausência de recorte, com a completude de um acontecimento e com a mínima edição possível (NOVAES, 2014).

\footnotetext{
${ }^{4}$ Agradeço a Kamilla Dantas e a Pablo Antônio pelas suas contribuições na primeira experimentação de edição do documentário. Destaco que Lutas artesanais passou por uma nova edição, mas mantém o título.
} 


\section{Nanduty}

ISSN:2317-8590

Entretanto, sempre há o recorte, nem que este seja dado pela escolha dos momentos de ligar e desligar uma câmara numa determinada circunstância.

\section{OS ENQUADRAMENTOS}

Assumir que um dado enquadramento de uma determinada prática deixa de fora vários outros enquadramentos, passa a ser o ponto de partida de uma reflexão ontológica preocupada com as produções de ausências.

Para Butler (2019), as produções de ausências atravessam o corpo, que se constitui de maneira social e interdependente. E, por isso, está a mercê de uma condição de precariedade compartilhada, que caracteriza a vida como uma vida vulnerável a priori. É claro que tal precariedade se revela maximizada para alguns e reduzida para outros, mas o reconhecimento de uma vulnerabilidade compartilhada seria o elo que constituiria a possibilidade (também frágil) de um "nós" - no sentido que Emmanuel Levinás dá ao termo. Embora nem tudo que esteja vivo seja considerado uma vida e em seu lugar habita algo que "não é preservado por nenhuma consideração, por nenhum testemunho, e que não será enlutada quando perdida" (2019: 33). É por isso, que para Butler - como para Susan Sontag, Roland Barthes e Michel Foucault - não basta reenquadrar uma moldura para que ela seja reveladora de vidas, até então, não reconhecidas, é necessário questionar as normas que constituem os enquadramentos como os reguladores de vidas e não-vidas.

Nesse sentido, Butler aposta em tatear novas coligações com o intuito de superar os impasses liberais, diz a autora: "O enfoque deveria recair menos nas políticas identitárias, ou nos tipos de interesses e crenças formulados com base em pretensões identitárias, e mais na precariedade e em suas distribuições diferenciais" (2019: 55). A aposta de Butler em tal coligação não pressupõe o compartilhamento nem a concordância em relação aos desejos, crenças ou autoidentificação, continua a autora: "Constituiria antes um movimento que

\footnotetext{
${ }^{5}$ Para uma história do filme etnográfico, começando por Baldwin Spencer, Rudolf Poch e Robert Flaherty, passando por Margaret Mead até Judith MacDougall e David MacDougall, ver Karl G. Heider (1995) e Peter Loizos (1995). Ambos concluem que o filme etnográfico não deve se restringir a uma "cultura-de-gueto" e que pode ser considerado como uma vertente do documentário. Para uma história recente do filme etnográfico, que o trata como documentário etnográfico, ver Coelho (2012). Para uma densa aproximação entre Sociologia e Cinema, ver Menezes (2004) e Menezes (2017).
} 


\section{Nanduty}

ISSN:2317-8590

abrigaria determinados tipos de antagonismos em curso entre seus participantes, valorizando essas diferenças persistentes e animadoras como o sinal e a essência de uma política democrática radical" (BUTLER, 2019: 55).

O filtro feminista pós-colonial acompanhou toda a produção audiovisual e contribuiu para um primeiro recorte, mas a minúcia do recorte foi realizada durante a experiência etnográfica. Uma experiência etnográfica é transformadora para quem dela participa. Mas qual seria o espaço, no contexto acadêmico, das músicas, das danças, dos risos, dos timbres, das performances, do choro, que contribuem para essa transformação vivenciada no terreno? Para Sylvia Novaes (2014), o audiovisual possibilita a elaboração de um discurso mais próximo do universo de pesquisa etnográfico.

Silvia Rivera Cusicanqui (2015), por sua vez, propõe que o uso do registro imagético pode ser um meio privilegiado na produção descolonial de memória e de conhecimento. Cusicanqui (2010) compreende episteme como um conjunto de saberes, inclusive os não-ditos. Com isso, não se busca o inefável, mas as várias formas de dizer contidas, sobretudo, na dimensão performativa da comunicação. Com essa premissa, Cusicanqui (2015) desenvolve a sociologia da imagem como uma forma de combater o colonialismo interno. A sociologia da imagem busca desarticular as hierarquias instrumentais na produção do conhecimento que privilegiam a palavra escrita em detrimento de outras formas de comunicação. A sociologia da imagem aposta, sobretudo, em uma epistemologia produzida na prática, com o olhar e com os gestos, pois no contexto colonial as palavras foram exaustivamente usadas com a função de produzir ausências e garantir formas de dominação. Como bem mostrou a socióloga feminista boliviana: 


\section{Nanduty}

ISSN:2317-8590

El anclaje geopolítico y el fundamento histórico para la noción de sociología de la imagen se halla en la propia realidad de los Andes, un espacio donde las palabras, más que designar la realidad, la encubren, y donde los lenguajes corporales, sonoros e iconográficos tienen una larga trayectoria como expresión de las experiencias del colonialismo, la resistencia y la memoria. Desde otra preocupación ética, es urgente hoy en día descolonizar la mirada, liberarla del bombardeo caótico y fragmentado de imágenes de todo tipo a que nos somete la sociedad mediática en que vivimos. Todo ello con el fin de alentar una reflexividad crítica en lxs estudiantes, a través de la observación desfamiliarizada de un entorno en el cual, de hecho, ya participan (CUSICANQUI, 2010: 34).

Para Cusicanqui (2015), não basta descrever a prática; é preciso também mostrá-la com os seus ritmos, tonalidades, gestos. O filme constitui, portanto, uma possibilidade de se relacionar com as palavras não apenas analiticamente, mas também de experimentá-las a partir da própria materialidade da sonoridade e do ritmo da fala. Isso porque não é apenas o significado que diz, o significante também diz muito. Ou melhor, como faz ressaltar Maria Irene Ramalho, "o significante tem total precedência sobre o significado" (2007: 262). Com isso, o audiovisual mobiliza outras alternativas de leitura e de percepção do universo empírico, que, por sua vez, permitem também outras possibilidades de crítica.

Desse modo, ao fazer uso de registros imagéticos e sonoros, apostei numa forma de dizer-mostrando no processo de produção de conhecimento, que passa pela aproximação do universo empírico, pela sua análise e pela partilha dos resultados.

Foram três os motivos que me mobilizaram a trabalhar com o audiovisual: exercitar a extensão ao contrário; promover diálogos, indo além do logocentrismo; fazer o retorno da pesquisa às associações. A seguir, esclareço cada um desses motivos.

1. Realizar a extensão ao contrário: trazer para os espaços de discussão da universidade as experiências concretas de subjetivações emergentes consiste na proposta que Boaventura de Sousa Santos chama de "extensão ao contrário", ou seja, não busca levar o conhecimento produzido dentro da universidade para fora de seus muros, mas trazer outros saberes para o diálogo com o conhecimento produzido dentro da universidade. Conceitua Santos: 


\section{Nanduty}

ISSN:2317-8590

A extensão ao contrário consiste na promoção de diálogos entre o saber científico ou humanístico, que a universidade produz, e saberes leigos, populares, tradicionais, urbanos, camponeses, provindos de culturas não ocidentais (indígenas, de origem africana, oriental, etc.) que circulam na sociedade. (SANTOS, 2004: 56).

Neste trabalho, o audiovisual foi usado como um meio para compartilhar os modos de saber-fazer das artesãs a partir de suas próprias vozes, gestos, ritmos. O principal propósito da conversa era conhecê-las. Com a produção do filme, espero trazer os saberes incorporados das artesãs indígenas para discussão no espaço acadêmico. Entretanto, não basta fazer a extensão ao contrário, é necessário também fazer o retorno da investigação para quem contribui com o processo empírico de produção de conhecimento.

2. Perguntar, observar e analisar não basta, é preciso fazer o retorno. Sem a pretensão de elaborar um quadro teórico sobre essa importante questão, a necessidade de se fazer um retorno deste trabalho foi um compromisso que assumi com as artesãs durante a investigação de campo. Embora todas as artesãs falem português, além de sua língua materna, muitas não têm facilidade com a leitura da língua na qual este texto está escrito.

3. Promover diálogos, indo além do logocentrismo: a produção de um conhecimento situado é fundamental para os estudos feministas (HARAWAY, 2009). Situado não apenas em seu contexto, mas no próprio corpo. A dimensão do corpo é indispensável para se tentar compreender o pensamento ameríndio. Por isso, não se trata apenas de documentar, mas de tentar perceber os modos de dizer a partir dos conhecimentos incorporados das artesãs. Nesse processo, a presença do corpo é absolutamente fundamental, pois aquilo que é verbalizado é somente um dos processos da comunicação. O corpo revela um conjunto de outras dimensões que têm justamente a ver com a dimensão performativa: o silêncio, o choro, a forma de expressar-se. As palavras podem ser absolutamente as mesmas, mas o sentido da comunicação pode ser totalmente alterado conforme uma série de materialidades corporais.

Desse modo, busquei não limitar o filme às entrevistas, pois reduzir as possibilidades do audiovisual ao discurso verbal seria reafirmar a hegemonia do logocentrismo. Para evitar

\footnotetext{
${ }^{6}$ Para uma discussão acerca do “corpo da artesã” ver Santos, Jenniffer Simpson (2019b) Descolonizar a prática: o artesanato como forma de afirmação ética.
} 


\section{Nanduty}

ISSN:2317-8590

uma redundância verbal, procurei relacionar imagens com voz e gestos para mostrar os detalhes que constituem o cotidiano das associações.

\section{ALGUMAS CONSIDERAÇÕES}

Em vários momentos, longe do campo, retornava ao material fílmico bruto e era levada novamente ao arquivo e repertório cultural do terreno. O tom das vozes, os risos, os volumes dos corpos recuperavam uma memória que me era necessária para escrever. Talvez, com isso, pude compreender o que Glória Anzaldúa chama de escrita orgânica: "não é com o papel que você cria, mas no seu interior, nas vísceras, no tecido vivo" (2000: 234). Uma vez que há todo um conjunto de linguagens que pode ser percebido além da verbalização, como nos lembra Diana Taylor (2003) - nem todo mundo expressa cultura através da escrita. Em Lutas artesanais, há: riso, choro, realização de pinturas corporais, danças, músicas, preparação de comidas, modos de trabalhar, crianças brincando com o artesanato, interação com a câmera, processo de venda, preparação da fibra de tucum e das sementes. Tudo isso são formas de dizer-mostrando que não cabem nas latitudes de um texto acadêmico e que possibilitam aproximar e ampliar a compreensão do universo de pesquisa. Só foi possível acompanhar e registrar essa diversidade de expressões a partir da relação de confiança que foi sendo criada.

\section{REFERÊNCIAS}

ACHUTTI, Luiz Eduardo Robinson. 1997. Fotoetnografia: um estudo de antropologia visual sobre cotidiano, lixo e trabalho. Porto Alegre, Tomo Editorial/Palmarinca.

ANZALDÚA, Glória. 2000. Falando em línguas: uma carta para as mulheres escritoras do terceiro mundo. Tradução de Édna de Marco. Revista Estudos Feministas, Florianópolis, 8(1):229-236.

BARTHES, Roland. 2015. A câmara clara. Tradução de Manuela Torres. Lisboa, Edições 70.

BENJAMIN, Walter. 2006. A obra de arte na época da sua possibilidade de reprodução técnica. In: BARRENTO, João. (org.). A Modernidade, Tradução de João Barrento. Lisboa, Assírio \& Alvim: 207-241.

BUTLER, Judith. 2019. Quadros de Guerra - quando a vida é passível de luto? $6^{\mathrm{a}}$ edição. Rio de Janeiro, Civilização brasileira.

CUSICANQUI, Silvia Rivera. 2010. “Ch'ixinakax utxiwa: Una reflección sobre prácticas y discursos descolonizadores”. Buenos Aires, Tinta Limón.

2015. Sociología de la Imagen. Miradas ch'ixi desde la historia andina. Buenos Aires, Tinta Limón. 


\section{Nanduty}

ISSN:2317-8590

HARAWAY, Donna. 2009. Manifesto ciborgue - ciência, tecnologia e feminismo-socialista no final do século XX. In: HARAWAY, Donna; KUNZRU, Hari; TADEU, Tomaz. (orgs). Antropologia do ciborgue: as vertentes do pós-humano. Tradução de Tomaz Tadeu. Belo Horizonte, Autêntica: 33-118.

KOSSOY, Boris. 2001. Fundamentos teóricos. In: KOSSOY, Boris. Fotografia e História. São Paulo, Ateliê Editorial: 33-50.

MENEZES, Paulo. 2004. O cinema documental como representificação: verdades e mentiras nas relações (im)possíveis entre representação, documentário, filme etnográfico, filme sociológico e conhecimento. In: NOVAES et al. (orgs.). Escrituras da imagem. São Paulo, FAPESP/Edusp: 21-48.

. 2017. Sociologia e cinema: Aproximações teórico-metodológicas. Programa de Pós-graduação em Ciências Sociais (UFJF), Juiz de Fora, 12(2):17-36.

NOVAES, Sylvia Caiuby. 2014. O silêncio eloquente das imagens fotográficas e sua importância na etnografia. Cadernos de Arte e Antropologia, Salvador, 3(2): 57-67.

RAMAlHO, Maria Irene. 2007. Poetas do Atlântico: Fernando Pessoa e o modernismo anglo-americano. Porto, Edições Afrontamento.

SANTOS, Boaventura de Sousa. 2004. A Universidade no Século XXI: para uma reforma democrática e emancipatória da universidade. São Paulo, Cortez.

SANTOS, Jenniffer Simpson dos. 2019a. Em que medida sobreviver é resistir? Porto Alegre, Cirkula.

. 2019b. Descolonizar a prática: o artesanato como forma de afirmação ética. In:

; FACHINETTO, Rochele Fellinni; DA SILVA, Rosimeri. (orgs.). Descolonizar a prática e o sexo. Porto Alegre, CirKula.

TAYLOR, Diana. 2013. In: TAYLOR, Diana. O arquivo e o repertório: performance e memória nas Américas. Tradução de Eliana Lourenço de Lima Reis. Belo Horizonte, Editora UFMG.

HEIDER, Karl G. 1995. Uma história do filme etnográfico. Tradução de Martha Arruda e Patrícia Monte-Mor. Cadernos de Antropologia e Imagem, Rio de Janeiro, (1): 31-34.

LOIZOS, Peter. 1995. A inovação no filme etnográfico. Tradução de Martha Arruda e Patrícia Monte-Mor. Cadernos de Antropologia e Imagem, Rio de Janeiro, (1): 55-64.

COELHO, Rafael Franco. 2012. Algumas notas sobre a história do cinema documentário etnográfico. Revista Comunicación, Piura, 10(1): 755-766. 